\title{
Transformation of Professional Training of Students in the Context of Education Modernization
}

\author{
TATYANA GUMENYUK ${ }^{1}$, VALERII KUSHNAROV ${ }^{2}$, IHOR BONDAR ${ }^{3}$, \\ VIKTORIIA HALUDZINA-HOROBETS ${ }^{4}$, YURII HORBAN 5 \\ ${ }^{1}$ Department of Event Management and Leisure Industry, KYIV NATIONAL UNIVERSITY OF CULTURE AND ARTS, \\ UKRAINE. E-mail: t.gumenyuk8@gmail.com \\ ${ }^{2}$ Department of Document Science and Information and Analytical Activity, KYIV NATIONAL UNIVERSITY OF \\ CULTURE AND ARTS, UKRAINE \\ ${ }^{3}$ Department of Design and Technologies, KYIV NATIONAL UNIVERSITY OF CULTURE AND ARTS, UKRAINE \\ ${ }^{4}$ Department of Public Relations and Journalism, KYIV NATIONAL UNIVERSITY OF CULTURE AND ARTS, UKRAINE \\ ${ }^{5}$ Scientific Library, KYIV NATIONAL UNIVERSITY OF CULTURE AND ARTS, UKRAINE
}

\begin{abstract}
Education, knowledge, information and communication form the basis for the professional development, initiative and well-being of the individual. The rapid progress of these technologies creates completely new oppotunities for achieving higher levels of development. The purpose of the article is to analyze how the modernization of education can affect the professional training of students. The authors analyzed the trends in the modernization of education, characterized the changes in the professional training of students, and also conducted a survey among the teaching staff and employers to determine what changes, from their point of view, should be supported; to enhance the methodological foundations of the professional and pedagogical training of a specialist. The authors proposed a method for the prospective assessment of changes in the professional training of university students in the context of education modernization, consisting of five stages. In the article, the authors presented a fragment of the approbation of this technique at the Kyiv National University of Culture and Arts. Based on the study, the authors made a forecast of trends in changes in the professional training of university students in the context of education modernization. Additionally, the authors identified and ranked the most likely social effects and risks as a result of the transformation of students' professional training.
\end{abstract}

Keywords: professional training, competence-based education, online education, practice-oriented education.

JEL Classification: H75, 121, 123

Received: 19 March 2021

Accepted: 2 April 2021 


\section{Introduction.}

The classical perception of the university form of training highly qualified specialists is being transformed and gradually unified: from the traditional European understanding of the university as a centre for the transfer and development of scientific knowledge to a globalised perception of the informational environment of education.

Education, knowledge, information and communication form the basis for the development, initiative and well-being of the human person. Knowledge and learning are humanity's most significant renewable resources [1]. Along with this, information and communication technologies have a substantial impact on almost every aspect of our lives. The rapid progress of these technologies opens up completely new prospects for achieving higher levels of development. The ability of these technologies mitigates many traditional barriers, especially those related to time and distance. Under favourable conditions, these technologies can be a powerful tool for economic growth, expanding employment opportunities and improving the quality of life.

Questions are becoming important today: what should be the professional training of future teachers, how it should change to contribute to the development of their professional competence, competitiveness in the labour market, professional mobility, active life and the professional position.

The growing complexity of labour makes new demands on the professional and general level of employment [2-3]. Widespread use in the production of control systems, flexible technologies leads to the fact that more and more employees are involved in creative work - from scientists and inventors to ordinary performers. This means that, in addition to in-depth specialist knowledge, the employee must have a high general cultural level, have a wide range of different qualities. This conclusion was reached by American scientists based on the results of special studies conducted at companies equipped with computer equipment. Among a large number of requirements for employees of these enterprises, we can highlight the following: a high level of intellectual development and professional competence; creative approach to the case, direct participation in the preparation of the program of work; the desire to improve the labour process, the perception of changes in production; ability to work effectively without supervision, developed sense of duty; critical mind, a high degree of curiosity; integrity of nature; sociability; ability to exchange ideas and help other team members [4-6]. Professional training of students must meet the modern requirements of society.

\section{Education modernisation trends.}

Looking at the modernisation of higher education as a permanent process causing changes in the professional training of students at a university requires an understanding of what changes have already taken place and which should be expected in the future.

The very term "modernisation" means "modernisation" and involves the introduction of modern features into society. P. Shtompka identifies three meanings of this concept:

- synonymous with all progressive change, when society moves forward according to the accepted scale of change;

- synonymous with modernity, when it comes to a set of social, political, cultural and intellectual transformations that have taken place in the West since the XVI century and reached its apogee in the XIX-XX centuries [7];

- efforts of underdeveloped or backward societies, aimed at catching up with the leading, most developed countries [8].

Thus, the term modernisation characterises a large number of simultaneous changes in different spheres of society.

At the present stage of development of professional training of university students, the following changes are distinguished (Fig. 1). 
Figure 1. Changes affecting the educational process

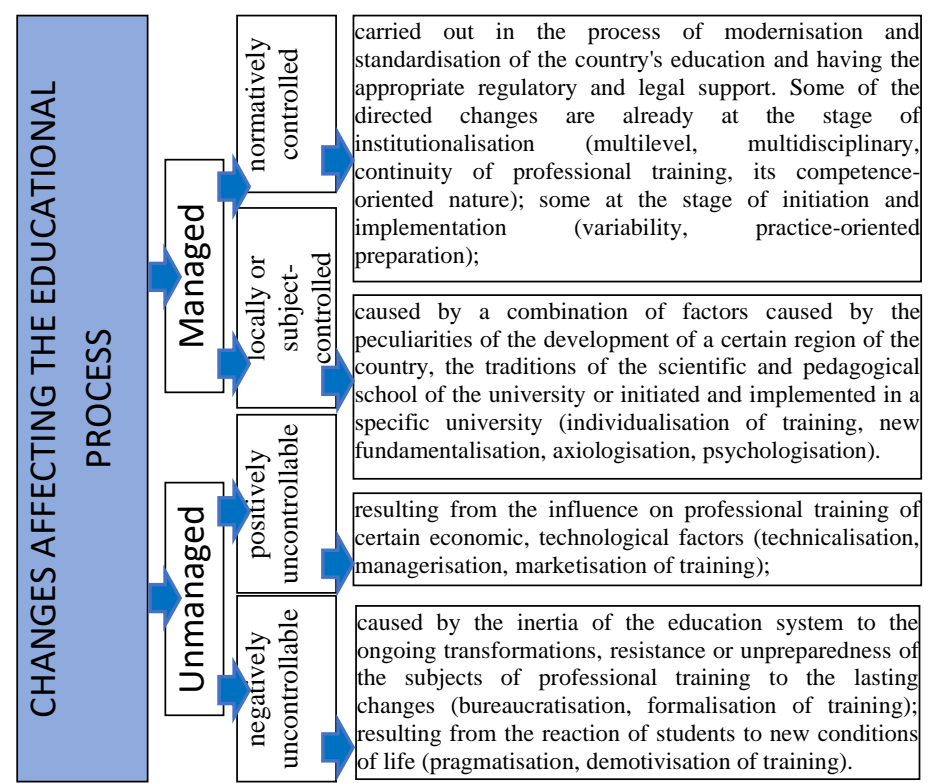

Table 1. Characteristics of changes in professional training of students

\begin{tabular}{|c|c|}
\hline Changes & Revealing the meaning \\
\hline $\begin{array}{l}\text { Multilevel and } \\
\text { multidisciplinary } \\
\text { training }\end{array}$ & $\begin{array}{l}\text { a three-level model of professional training for undergraduate - graduate - } \\
\text { postgraduate programs; the opportunity to continue studying in a magistracy in } \\
\text { another speciality; }\end{array}$ \\
\hline $\begin{array}{l}\text { Continuity of } \\
\text { preparation }\end{array}$ & $\begin{array}{l}\text { conditions for the influx of people of different ages into the system: the } \\
\text { possibility of a person's return to systematic vocational education after or in the } \\
\text { course of practical professional activity; "Synchronisation" of the content of } \\
\text { psychological and pedagogical disciplines (by didactic units, thematic blocks, } \\
\text { mastered competencies, etc.) contributes to the continuity of the accumulation } \\
\text { of knowledge, consistency in the development of certain competencies; }\end{array}$ \\
\hline $\begin{array}{l}\text { Competence-based } \\
\text { training }\end{array}$ & $\begin{array}{l}\text { the transition from linear to non-linear organisational forms - modular; an } \\
\text { understanding of the very professional training of future teachers at the } \\
\text { university (not only as a process of mastering the norms, samples and rules of } \\
\text { the professional and pedagogical activity but also as a process of the formation } \\
\text { of subject experience); the nature of the interaction between the teacher and } \\
\text { the student (change from the formal-role nature of interaction to constructive- } \\
\text { interpersonal), which leads to the emergence of new role-playing positions of } \\
\text { the teacher (coach, coach, academic consultant, tutor, designer of educational } \\
\text { materials, etc.) and an increase in students' independence; technologies for the } \\
\text { preparation of future teachers at the university, which become more } \\
\text { professionally-oriented (contextual, project, training, simulative, reflective); } \\
\text { resource support for the training process (informational, methodological, } \\
\text { personnel, etc.); }\end{array}$ \\
\hline $\begin{array}{l}\text { Practice-oriented } \\
\text { training }\end{array}$ & $\begin{array}{l}\text { passing practice ceases to be a formality; deepening professionally-oriented } \\
\text { practices (network, distributed; continuous, dispersed, clinical, internship, } \\
\text { professional tests, etc.); solution of practice-oriented educational materials and } \\
\text { tasks within the framework of academic disciplines (cases, educational and } \\
\text { professional tasks, situational tasks, etc.); increase in hours for independent } \\
\text { work; project execution, research, testing, etc. within the taught disciplines; }\end{array}$ \\
\hline $\begin{array}{l}\text { Individualisation of } \\
\text { preparation }\end{array}$ & $\begin{array}{l}\text { The possibility of a free schedule for studying disciplines studying the opinions of } \\
\text { students at the end of the taught course; }\end{array}$ \\
\hline $\begin{array}{l}\text { Changing } \\
\text { fundamentalisation }\end{array}$ & $\begin{array}{l}\text { a shift from the subject and methodological training (in-depth training of a } \\
\text { specialist - "education in-depth") towards psychological and pedagogical } \\
\text { training (versatile humanitarian training - "education in breadth"). }\end{array}$ \\
\hline
\end{tabular}


The cardinal renewal of society, its openness and democratisation led to the transition from the ideology of collectivism to the autonomy of the individual, the isolation of man upon himself, when the social and state forms of regulation of the way of life and behaviour of individuals decrease.

Such transformations have led to a change in the scale of values of today's youth. Besides, many socio-economic problems (unemployment, uncertainty about the future, etc.) increasingly encourage student youth to take a pragmatic attitude towards everything they do. They do not want to be deceived, and therefore, they are inclined not to accept everything as accurate and are ready to double-check what is broadcast to them in the process of studying at the university; strive for practical action and try to find the meaning of life in the present, here and now, and not dream of a bright ghostly future.

The pragmatism of the professional training of future teachers is a process due to the spread of the professional-market type of goal-setting in teaching, taking into account the pragmatic aspirations of students.

It is these tendencies that dictate the change in the professional training of students (Table 1).

The authors conducted a survey of the views of teaching staff and employers on what changes, in their opinion, should be supported (Fig. 2).

Figure 2. Changes affecting the educational process

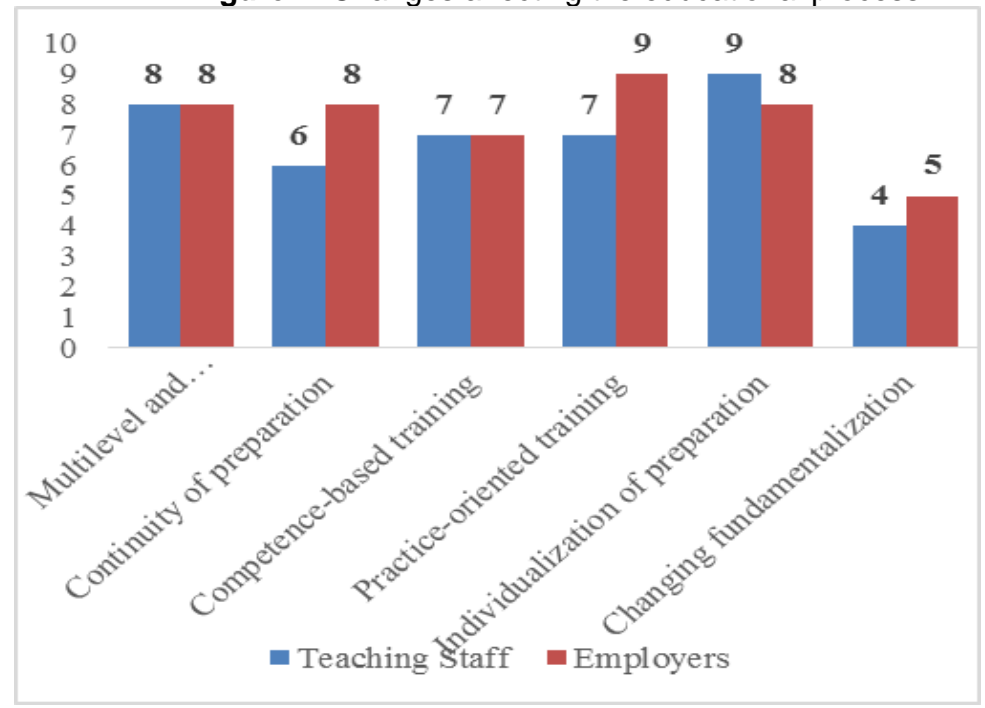

It should be noted that opinions agree (deviations are insignificant) - this is a positive factor since the view of what a student should eventually become as a professional is the same for those who train him and those for whom he is preparing.

\section{Methodological bases of professional and pedagogical training of a specialist.}

Modern research related to specialist training is outlined by qualitatively new requirements for the level of training and his ability to organise practical work, research, generalise methodological experience, critically evaluate the results of their own work, work on themselves.

Compliance with the set of these requirements can be ensured by the formation of the future specialist levels of methodological knowledge (Fig. 2) [9-12].

The content of the highest, philosophical level of the methodology consists of the general principles of cognition and the categorical apparatus of science in general. Current philosophical trends include phenomenology, praxeology, semiotics, axiology. 
Figure 3. Levels of methodological knowledge of the future specialist

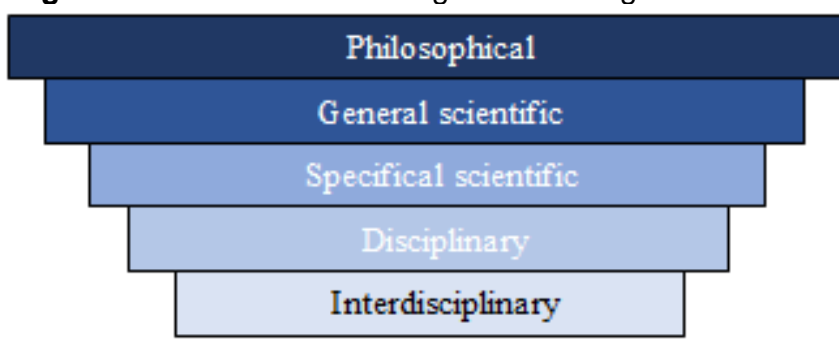

The philosophical level acts as a meaningful basis of any methodological knowledge, determines the worldview approaches to the process of cognition and transformation of reality. A vital component of this level of the methodology is the initial philosophical position and the corresponding methods that guide the researcher to know the object in its natural development. The philosophical level of methodology, which is based on the dialectical principle, consists of the general tenets of cognition:

- objectivity and certainty of phenomena by certain conditions, causes, factors;

- a holistic approach to the study of phenomena and processes;

- consideration of the phenomenon in its connections and interaction with other phenomena;

- study of the phenomenon in its development.

These methodological principles provide a systematic focus of scientific research and practical knowledge of the object: the principle of relationship with the external environment, according to which no phenomenon can be self-sufficient, because it improves according to changes in the external environment; the principle of integrity, according to which the object under study acts as separate parts, organically integrated into a single whole; the principle of determinism - the objective causal conditionality of phenomena; genetic principle - the study of the phenomenon in its development.

At the general scientific level, systemic and activity approaches have retained their importance and the theory of self-organisation - synergetics - is beginning to spread. The general scientific methodology considers the logical methods of general nature, laid down in the foundation of human thinking: analysis and synthesis, abstraction and generalisation, induction and deduction, explanation and understanding, description and definition. Some procedures make up the cognitive process of the empirical level - an observation with an empirical illustration, experiment and explanation that completes it, an empirical hypothesis, as well as empirical generalisation. The system, algorithmic, system-optimisation, structural-functional, cybernetic, probabilistic principles and approaches, methods of modelling, formalisation, etc. are also general scientific. There is often a "mixing" of methodological principles, approaches and methods by scientists. This level of methodology has an interdisciplinary nature, which summarises the common features of scientific activity in its various forms. A general scientific method is usually a systematic approach that reflects the general relationship and interdependence of phenomena and processes of the surrounding reality. It orients researchers and practitioners to the need to interpret the wonders of life, socialisation and training of people as systems that have a specific structure and their laws of functioning.

The specific scientific level of methodology considers a set of theoretical provisions, patterns, methodological approaches, technologies, research principles and procedures used in a particular scientific field. The methodology of a particular science contains both problems specific to scientific knowledge in this field, and issues raised at higher levels of methodology (general scientific and philosophical). The content of the specific scientific level of the methodology is the analysis of problems related to the specifics of scientific research in each particular field of scientific knowledge. This specificity is determined by a number of factors: the subject of study of a particular science; basic methods of obtaining knowledge about the subject of research; ways to construct explanations (theories). The concrete-scientific level consists in the development of concepts, receptions, 
principles, methods of the decision of concrete problems of science which are embodied in decisions, algorithms of calculations, experiments.

The disciplinary level of the methodology is a methodological project that determines the direction of research, patterns of education and upbringing, personal development; interpretation of results and their introduction into theory. The disciplinary level includes specific intra-disciplinary methods, techniques and research techniques, which are interpreted as methods used in a particular scientific discipline. It should be noted that at this level, the provisions of the philosophical, general scientific and concrete-scientific levels of the methodology are specifically "refracted" and accumulated. At the disciplinary level of research, many different methods and techniques are used, each of which has its specific meaning, due to various cognitive situations designed to solve a particular problem. At the same time, the methodology of any particular scientific discipline contains not only the means of outstanding research, such as conditions and rules of the experiment, requirements for the representation of data, methods of processing, etc. but also methodological tools and techniques used in related sciences and scientific disciplines, as well as general scientific methodological tools and techniques.

The interdisciplinary level. Interdisciplinarity is seen as a collision, interpenetration, synergy of different disciplines, which involves the development of integration processes, growing interaction, mutual enrichment of methods, tools for obtaining new scientific knowledge. Polydisciplinarity means the joint study of a complex object in different disciplines (for example, the study of human psychology, genetics, sociology, etc.). Transdisciplinarity implies that research goes beyond disciplinary boundaries when research schemes are transferred from one field to another. The interdisciplinary level of the methodology includes a group of multidisciplinary methods, including synthetic, integrative techniques used at the intersection of scientific disciplines. These approaches consider scientific disciplines in such a perspective that avoids many common mistakes when concepts borrowed from one field of knowledge are uncritically transferred to others; when metaphors that are acceptable in the context of some scientific approaches are used in other areas of knowledge as scientific concepts. An important task is a clear understanding of the categorical meaning of some disciplines and the refusal to extend these categorical relations to other areas automatically. Studying pedagogical objects with their help gives an opportunity to gain new knowledge. Interdisciplinary tools include cultural, ethnopedagogical, integrative, organisational, historical, informational and other approaches.

The effectiveness of development and usefulness of all pedagogical science depends on the level of development and integrity of all levels of pedagogical methodology. The first three levels of procedure ensure the compliance of pedagogical research with the value system of modern society (the first level); the most effective ways to solve social problems (second level); trends in the development of pedagogical science (third level) [13]. And the fourth and fifth levels provide the technological implementation of the conceptual foundations of the study, formed by the first three levels of methodology.

\section{Results: Predicting trends in the professional training of university students in the context of education modernisation.}

According to the logic of prospective analysis, forecasting changes in vocational training of students in the context of modernisation of education is carried out on the basis of modelling the current situation of the development of vocational training, scenario-based trends in changes in vocational training of students, prospective assessment of the effects and risks of changes in vocational training.

The method of prospective assessment of changes in the professional training of university students in the context of education modernisation involves the following sequence of stages of its construction and implementation: 1 . organisational and target; 2 . information and research; 3. procedural and diagnostic; 4 . analytic-reflexive; 5 . efficient. 
Contents of the stages of prospective assessment; methods used at each stage; the tools are presented in Fig. 4.

Figure 4. Methodology for prospective assessment of changes in professional training of university students in the context of education modernisation

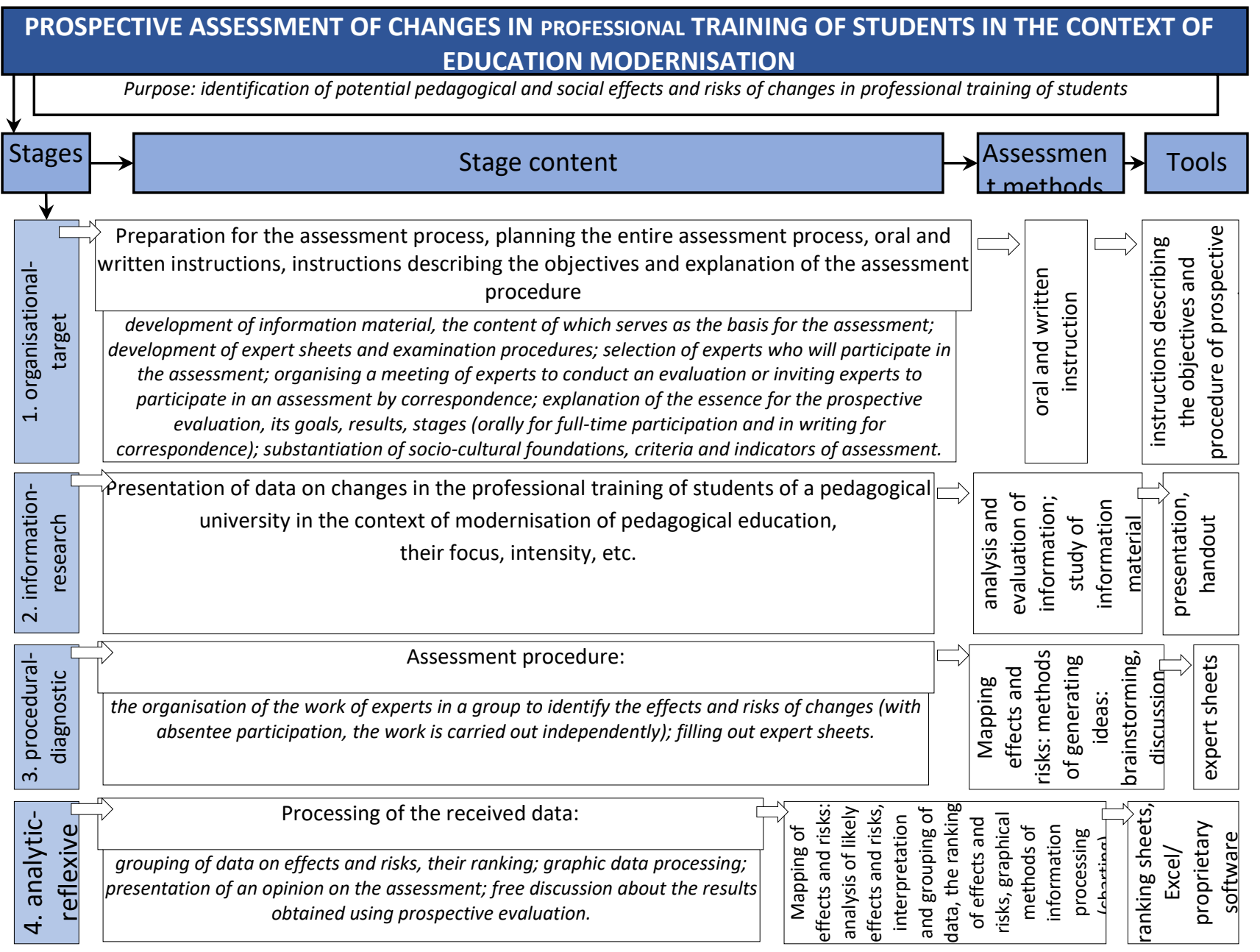

\begin{tabular}{|c|c|c|c|}
\hline \multirow[b]{2}{*}{ 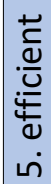 } & Performance evaluation: & \multirow{2}{*}{ 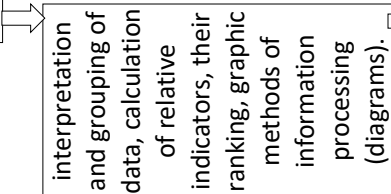 } & \multirow[b]{2}{*}{ 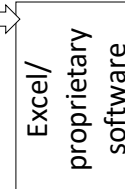 } \\
\hline & $\begin{array}{c}\text { Prospective assessment indicators can be various kinds of dynamics - improvement in } \\
\text { the work of a system or institution, changes in activity. Indicators: development of the } \\
\text { professional community; development or emergence of new norms, patterns and rules of } \\
\text { professional activity; changes in the activities of the university. }\end{array}$ & & \\
\hline
\end{tabular}

We would like to dwell separately on stages 3 and 4 (procedural-diagnostic and analytic-reflexive), where the technique of mapping risks, pedagogical and social effects of changes in the professional training of university students in the context of modernisation of education were used, which is widely used in prospective studies of the Council of Europe. Mapping risks, pedagogical and social effects involve the following sequence of actions:

1.Generating ideas about possible effects and risks;

2. interpretation and sorting (grouping of effects and risks);

3. ranking of effects and risks;

4. graphical presentation of processing results.

The prospective assessment procedure involved the work of experts in mini-groups (5 people each) to generate ideas and fill out expert sheets. Then, the experts discussed the results of the work in mini-groups and compiled a generalised expert list, reflecting the expected effects and risks of changes in the professional training of university students in the context of modernisation of 
education. Further, the effects were divided into two groups - social and pedagogical. After that, each expert should rank separately social effects, pedagogical effects and risks according to their severity (i.e., the probabilistic nature of their manifestation in the future - the ranking began with effects and risks that will manifest themselves more strongly and further, to a lesser degree). At the end of the prospective assessment procedure, each mini-group wrote a conclusion on the extent to which the effects and risks of changes in vocational training identified by them reflect the success of the ongoing modernisation of education. The processing of the ranking data was carried out by the researcher independently after the group work of the experts.

Let us present a fragment of the results of the assessment carried out at Kyiv National University of Culture and Arts (Table 2, Fig. 5).

Fig. 5 clearly shows which social effects and risks experts consider the most likely as a result of the transformation of professional training of students in the context of education modernisation.

Table 2. Ranking the effects and risks of changes in the professional training of university students in the context of education modernisation (fragment: social impacts and risks)

\begin{tabular}{|c|c|c|c|c|c|c|c|c|c|}
\hline \multirow{2}{*}{ Effects and risks } & \multicolumn{8}{|c|}{ Expert estimates } & \multirow{2}{*}{ Total } \\
\hline & 1 & 2 & 3 & 4 & 5 & 6 & $\ldots$ & 15 & \\
\hline \multicolumn{10}{|l|}{ Social Effects: } \\
\hline $\begin{array}{l}\text { S1. increasing the attractiveness of a specialised university, the } \\
\text { specificity of which ensures the continuous nature of professional } \\
\text { training }\end{array}$ & 3 & 6 & 1 & 6 & 1 & 2 & $\ldots$ & 4 & 2,0 \\
\hline $\begin{array}{l}\text { S2. development of the university brand, positioning it in the } \\
\text { educational services market }\end{array}$ & 1 & 2 & 4 & 2 & 3 & 1 & $\ldots$ & 1 & 3,5 \\
\hline $\begin{array}{l}\text { S3. continuity of learning (when parents bring their children to the } \\
\text { alma mater) }\end{array}$ & 2 & 1 & 5 & 5 & 4 & 5 & $\ldots$ & 7 & 3,8 \\
\hline S4. more conscious and quick "entry" into the profession & 5 & 5 & 2 & 4 & 2 & 3 & $\ldots$ & 6 & 3,8 \\
\hline $\begin{array}{l}\text { S5. an increase in the number of professional communities } \\
\text { (associations, unions, etc.) }\end{array}$ & 7 & 3 & 7 & 1 & 8 & 6 & $\cdots$ & 5 & 5,1 \\
\hline $\begin{array}{l}\text { S6. continuous professional development contributing to the } \\
\text { professional success and competitiveness of a specialist }\end{array}$ & 8 & 7 & 6 & 8 & 6 & 8 & $\ldots$ & 3 & 5,6 \\
\hline $\begin{array}{l}\text { S7. the spread of views on education as a service sector, which will lead } \\
\text { to further commercialisation of scientific and professional activities }\end{array}$ & 6 & 8 & 8 & 3 & 5 & 7 & $\ldots$ & 2 & 5,6 \\
\hline $\begin{array}{l}\text { S8. dissemination of ideas about the professional and pedagogical } \\
\text { activity as a career }\end{array}$ & 4 & 6 & 3 & 7 & 7 & 5 & $\ldots$ & 8 & 6,6 \\
\hline \multicolumn{10}{|l|}{ Risks: } \\
\hline $\begin{array}{l}\text { R1. expansion of functionality and intensification of labour lead to } \\
\text { overload and emotional burnout of specialists }\end{array}$ & 3 & 3 & 3 & 1 & 3 & 4 & $\ldots$ & 2 & 1,6 \\
\hline $\begin{array}{l}\text { R2. superficiality of knowledge due to the expansion of academic } \\
\text { freedom of students in the choice of educational services }\end{array}$ & 1 & 3 & 1 & 2 & 2 & 1 & $\ldots$ & 1 & 2,5 \\
\hline R3. risk of reducing the quality of subject training of future specialists & 4 & 2 & 4 & 3 & 1 & 2 & $\ldots$ & 3 & 2,8 \\
\hline $\begin{array}{l}\text { R4. refusal to understand professional activity as a vocation and to } \\
\text { consider it only as entrepreneurship, business }\end{array}$ & 2 & 4 & 2 & 4 & 4 & 3 & $\ldots$ & 4 & 3,4 \\
\hline
\end{tabular}

Figure 5. Ranking the effects and risks

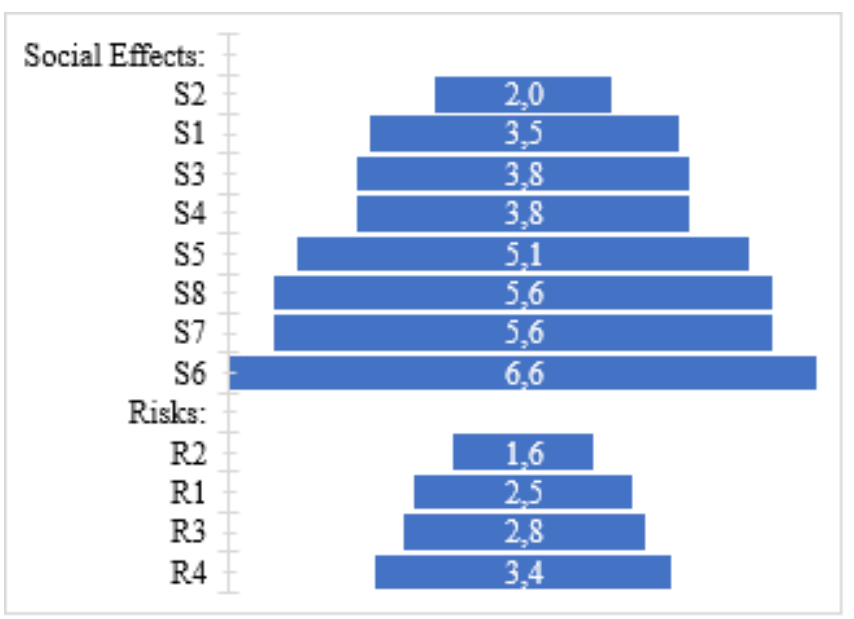




\section{Discussion.}

Experts consider S1-S4 to be the most probable social effects as a result of the transformation of professional training of students. It should be noted that these effects relate directly to the university and to the profession, while aspects related to professional communities and changes in ideas about the future job fade into the background. As for the risks, the experts believe that the most probable state of affairs is when students will not know their profession in-depth, most likely a little bit. We believe that this is a rather important aspect of the professional training of future specialists and it is impossible to reduce its quality in the context of modernization of education; therefore it is necessary to apply additional measures to prevent the onset of this type of risk.

\section{Conclusion}

Modern education helps young people to enter the context of contemporary culture, the formation of the individual as a subject and strategist of a life worthy of man. The individual must be able to independently build their lives, realize and master their attitude to themselves, society, the values produced by this society, nature, the degree of self-realization of elemental forces, internal potentials. The culminating stages of creative search are the stages when a person makes decisions about the defining problems of his own life. The development of future professionals as individuals, as subjects of activity, is an essential goal of higher professional education and can be considered as its system-forming factor. The main attention should be paid to the intellectual development of students. A higher vocational school, being a social institution, is designed to prepare its graduate for future socio-professional life.

\section{References}

1. UNESCO's international commission starts reflection on the futures of education - Join the global debate, Online available from https://en.unesco.org/news/unescos-international-commissionstarts-reflection-futures-education-join-global-debate

2. Wardale, D. (2020). Improving international student transition to professional employment. Sixth International Conference on Higher Education Advances, Universitat Politecnica de Valencia, 283291.

3. Gott, T., Bauer, T., \& Long, K. (2019). Student Leadership Today, Professional Employment Tomorrow, New Directions for Student Leadership, 162, 91-109.

4. Jiří, D. (2016). Gender influence on students' requirements of employee benefits. Journal on Efficiency and Responsibility in Education and Science, 9(4), 2336-2375.

5. Sokolova, A. (2018). The new system of qualification requirements for personnel changes the requirements for employees of personnel services. Journal of Public Administration, 5(1), 61-67.

6. Daling, L., Schröder, S., Haberstroh, M., \& Hees, F. (2018). Challenges and Requirements for Employee Qualification in the Context of Human-Robot-Collaboration. 2018 IEEE Workshop on Advanced Robotics and its Social Impacts (ARSO), Genova, Italy, 85-90.

7. Concept and theory of modernisation - Political Sociology, Online available from https://testmyprep.com/subject/sociology/concept-and-theory-of-modernization-political

8. Shtompka, P. (1996). Sociology of social changes, Nauka, Moscow.

9. Koishygullova, L., Egenisova, A., Zhaxylikova, K., Magauina, G., \& Uzakpayeva. (2017). Methodological bases of professional competence formation of the future specialists. Journal of Engineering and Applied Sciences, 12(3), 766-768.

10.Sergeeva, M., Bondarenko, N., Shebzuhova, T., Vartumyan, A., Shuisky, A., \& Mazurenko, A. (2019). Legal culture formation of a future specialist. Humanities \& Social Sciences Reviews, 7(4), 13-19. 
11.Baitukayeva, A., Aktayev, D., Erkin, A., Shagirova, K., \& Krykbaeva, S. (2015). Formation of the Professional Competence of the Future Specialists. Procedia - Social and Behavioral Sciences, 185, 141-145.

12.Rotaru, I. (2015). Knowledge Management - A Necessity For The Training Of Future Specialists Of The Sustainable Enterprises. Acta Universitatis Cibiniensis. Technical Series, 67(1).

13.Kruty, K., Zdanevych, L., Demianenko, O., Pakhalchuk, N., Perminova, L., \& Garachkovska, O. (2019). E-learning methods in students' education. International Journal of Innovative Technology and Exploring Engineering, 8(12), 251-256. 